\title{
ESTAQUIA DE AMOREIRAS SUBMETIDAS A PRÉ-TRATAMENTO COM ÁGUA E DIFERENTES SUBSTRATOS ORGÂNICOS
}

\section{MULBERRY CUTTINGS SUBMITTED TO PRE-TREATMENTS WITH WATER AND DIFFERENT ORGANIC SUBSTRATES}

\author{
Naelly Caroline de Souza GALETI ${ }^{1}$ \\ Willian CICHELERO ${ }^{2}$ \\ Roxelle Ethienne Ferreira $\mathrm{MUNHOZ}^{3}$ \\ Patrícia da Costa ZONETTI ${ }^{4}$
}

\begin{abstract}
RESUMO
Este trabalho teve o objetivo de avaliar a utilização de substratos suplementados com resíduos orgânicos e de prétratamento com água no desenvolvimento de estacas de amoreira cultivares Miura, SK 1 , SK 4 e IZ 6/2. O experimento consistiu de seis tratamentos: T1- Pré-tratamento e substrato com bagaço de cana-de-açúcar; T2- Pré-tratamento e substrato com esterco de galinha; T3- Pré-tratamento com água sem resíduo orgânico; T4- Substrato com bagaço de cana-de-açúcar; T5- Substrato com esterco de galinha; T6- Substrato sem complemento de resíduo orgânico. O pré-tratamento consistiu em deixar as estacas imersas na água por um período de $24 \mathrm{~h}$. A porcentagem de plantas com brotos foi estimada de dois em dois dias. Após o $70^{\circ}$ dia foram avaliados a porcentagem de sobrevivência e a altura média dos brotos. Os melhores resultados de enraizamento foram obtidos quando as estacas foram submetidas a imersão em água antes do plantio. $\mathrm{O}$ uso de substratos acrescidos com bagaço de cana-de-açúcar e esterco de galinha não mostrou-se efetivo para propagação por estaquia de amoreira.
\end{abstract}

Palavras-chave: Propagação; Morus sp.; sericicultura.

\section{ABSTRACT}

The use of different substrates supplemented with organic waste and pre-treatment with water in the development of mulberry cuttings cultivars Miura, SK 1 SK 4 and IZ $6 / 2$ was evaluated by the present study. Six different treatments were performed: T1 - water pre-treatment and crushed sugar cane substrate, T2 - water pre-treatment and chicken manure substrate; T3 - water pre - treatment without organic residue; T4 - crushed sugar cane substrate; T5 - chicken manure substrate, T6 - substrate with no additional organic waste. Water pre-treatment meant leaving the cuttings immersed in water for a period of 24 hours. The percentage of plants with buds was estimated every two days. After 70 days, the fixation percentage, the daily fixation index (IPD) and the average tillers height were evaluated. The best rooting results were obtained when the cuttings were immersed in water before planting. The crushed sugar cane substrate showed better fixation rates than the chicken manure substrate; however, the plants treated with chicken manure had a better sprout growth. The substrate increased with crushed sugar cane and chicken manure was not shown to be effective in cutting propagation of mulberry.

Key-words: Propagation; Morus sp.; sericulture.

\footnotetext{
${ }^{1}$ Licenciada em Ciências Biológicas pelo Centro Universitário de Maringá, Maringá, PR, Brasil. E-mail: na caroline17@hotmail.com ${ }^{2}$ Acadêmico do Curso de Agronomia do Centro Universitário de Maringá, Maringá, PR, Brasil. E-mail: williancichelero98@hotmail.com ${ }^{3}$ Bióloga mestre em Agronomia e doutoranda em Genética e Melhoramento p ela Universidade E stadual de Maringá, Maringá, PR, Brasil. E-mail: roxellem@hotmail.com

${ }^{4}$ Bióloga doutora em Agronomia e docente da Universidade Federal do Paraná, Campus Palotina. Rua Pioneiro, 2153. CEP: 85950.000 , Palotina, PR, Brasil. E-mail: patriciazonetti@ufpr.br. Autor para correspondência.
} 
GALETI, N. C. S. et al. Estaquia de amoreiras submetidas...

\section{INTRODUÇÃO}

A sericicultura é a atividade agropecuária de criação do bicho-da-seda (Bombyx mori Linneaus, Lepidoptera: Bombycidae) destinada à produção de casulos que são utilizados para a obtenção de fios de seda. Trata-se de uma atividade bastante antiga que é praticada em diversas partes do mundo há cerca de 5000 anos. Esta criação está intimamente relacionada com a cultura da amoreira, uma vez que o inseto é monofágico, e suas fases larvais alimentam-se exclusivamente de folhas frescas de amoreiras (Hanada e Watanabe, 1986).

O Brasil é um país com destaque na sericicultura mundial, sendo o sexto maior produtor mundial de casulos e o quarto de fios de seda. $\mathrm{Na}$ safra 2008/2009 a produção brasileira foi de $4.835 \mathrm{t}$ de casulos, sendo que o estado do Paraná nos últimos 10 anos destacou-se como o maior produtor nacional de casulos verdes, sendo responsável por mais de $92 \%$ da produção nacional. Na produção paranaense estão envolvidos 219 municípios onde se pratica a atividade sericícola, contando com 4.524 criadores totalizando 5.002 barracões. A área de amoreiral destinada a sericicultura no estado foi de 11.464 ha na safra 2008/2009 (SEAB, 2009).

A amoreira possui um grande número de cultivares que são selecionadas principalmente para a produção de folhas (Murari \& Marchini, 2001; Meneguim et al., 2007). A seleção do material genético visando tal característica é importante, visto que o principal destino das mesmas está envolvido com a sericicultura (Mantovani et al., 2006), implicando diretamente na qualidade físicoquímica do fio de seda e na produtividade (Miranda et al., 2002).

A utilização de estacas na propagação da amoreira é uma prática que tem sido utilizada, uma vez que, durante o período de dormência, por ocasião da poda, obtém-se grande quantidade de ramos que podem ser utilizados na propagação. Segundo Caldwell (1984), os ramos herbáceos, retirados por ocasião da poda de inverno, podem maximizar a utilização do material vegetal e não apenas eliminá-lo como subproduto. Desta forma a instalação do amoreiral se dá quase que exclusivamente por estaquia. O substrato utilizado em tal processo é fator imprescindível para o ideal enraizamento. Os mesmos podem ser enriquecidos com substâncias orgânicas, melhorando o arejamento e promovendo maior retenção da água no substrato (Hanada \& Watanabe, 1986).
Outra proposta para melhorar o enraizamento de estacas de amoreira é a imersão da base das estacas em água por um período de 24 $\mathrm{h}$ antes do plantio (Okamoto et al., 2005). Esta metodologia é simples e não acarreta em custos no sistema produtivo e tem sido facilmente aceita pelos sericultores.

Visando encontrar metodologias efetivas e simples para o aumento da taxa de sobrevivência na produção de mudas de amoreiras por estacas, este trabalho teve como objetivo avaliar a utilização de substratos com resíduos orgânicos e de prétratamento no desenvolvimento de estacas de Morus alba L., variedades Miura, SK 1, SK 4 e IZ $6 / 2$.

\section{MATERIAL E MÉTODOS}

As estacas de amoreira cultivares Miura, SK 1 , SK 4 e IZ 6/2 foram obtidas de ramos maduros e lenhosos do Banco de Germoplasma da espécie, localizado no IAPAR (Instituto Agronômico do Paraná) no município de Londrina, no estado do Paraná.

Foram utilizados seis tratamentos, sendo estes T1: pré-tratamento com imersão em água e substrato enriquecido com bagaço de cana-deaçúcar, na proporção de 3:1:1:1 (solo: areia: húmus: bagaço de cana-de-açúcar); T2: pré-tratamento com imersão em água e substrato enriquecido com esterco de galinha na proporção de 3:1:1: 1/2 (solo: areia: húmus: esterco de galinha); T3: prétratamento com água em substrato considerado controle, na proporção de 3: 1: 1, (solo: areia: humus) sem a presença de resíduo orgânico; T4: ausência de pré-tratamento com imersão em água, com substrato enriquecido com bagaço de cana-deaçúcar, na proporção de 3:1:1:1, (solo: areia: bagaço de cana-de-açúcar); T5: ausência de prétratamento com imersão em água, com substrato enriquecido com esterco de galinha na proporção de 3:1:1: $1 / 2$ (solo: areia: húmus: esterco de galinha); T6: ausência de pré-tratamento com imersão em água, com substrato controle; na proporção de 3:1:1, (solo: areia: húmus). O pré-tratamento consistiu em deixar as estacas totalmente imersas na água na posição horizontal por um período de 24 $\mathrm{h}$ antes do plantio.

O substrato foi analisado, já misturado na proporção de 3:1:1 (solo: areia: húmus). O resultado da análise do substrato encontra-se na Tabela 1 e dos resíduos orgânicos na Tabela 2.

TABELA 1 - Análise química do solo utilizado para o enraizamento de estacas de amoreira, Maringá, Paraná, 2008

\begin{tabular}{|c|c|c|c|c|c|c|c|c|c|c|c|c|c|c|}
\hline \multicolumn{2}{|c|}{$\mathrm{pH}$} & $\mathrm{Al}^{3^{+}}$ & $\mathrm{H}^{+}+\mathrm{Al}^{3^{+}}$ & $\mathrm{Ca}^{2+}$ & $\mathrm{Mg}^{2}$ & $\mathrm{~K}^{+}$ & SB & CTC & $P$ & $\mathrm{C}$ & $\mathrm{V}$ & $\mathrm{Ca}$ & $\mathrm{Mg}$ & $\mathrm{K}$ \\
\hline $\mathrm{CaCl}_{2}$ & $\mathrm{H}_{2} \mathrm{O}$ & \multicolumn{4}{|c|}{ - $\mathrm{cmol}_{\mathrm{C}} \mathrm{dm}^{-3}$} & --.-- & ------ & ----- & $\mathrm{mg} \mathrm{dm}^{-3}$ & $\mathrm{~g} \mathrm{dm}^{-3}$ & & - & - & \\
\hline 7,1 & 7,5 & 0,0 & 1,74 & 7,89 & 2,45 & 0,86 & 11,2 & 12,94 & 114,2 & 13,03 & 86,5 & 61,0 & 18,9 & 6,7 \\
\hline
\end{tabular}

SB- soma de bases; CTC - capacidade de troca catiônica; V- índice de saturação por bases. 
GALETI, N. C. S. et al. Estaquia de amoreiras submetidas...

TABELA 2 - Composição química dos resíduos orgânicos utilizados na complementação do substrato para o enraizamento de estacas de amoreira, Maringá, Paraná, 2008.

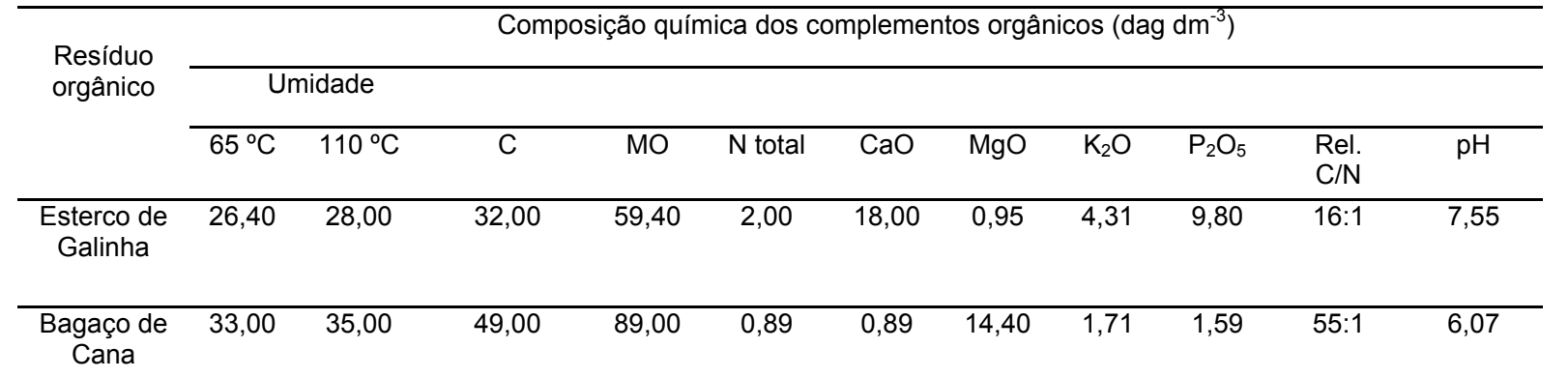

Foram utilizadas estacas com $20 \mathrm{~cm}$ de comprimento com corte em bisel na base. Aproximadamente $2 / 3$ destas foram enterrados nos diferentes substratos. As estacas foram plantadas em sacos de polietileno preto. Foram realizadas quatro repetições de cada tratamento. A parcela experimental constou de dez unidades.

O experimento foi conduzido em casa de vegetação no Centro Universitário de Maringá, situado no município de Maringá, Paraná, em agosto de 2008. O ensaio recebeu irrigação por aspersão duas vezes ao dia durante dez minutos. Foi avaliada a cada dois dias a presença de brotos nas estacas e determinado a porcentagem de brotamento nestes dias até $25^{\circ}$ dia da instalação do ensaio. Após $070^{\circ}$ dia foram avaliadas a porcentagem de sobrevivência e altura média dos brotos.

O delineamento experimental foi de blocos ao acaso no esquema fatorial $4 \times 6$. Os dados foram submetidos à análise de variância. As médias entre os tratamentos comparadas pelo teste de Scott-Knott (1974) a 5\% de significância. Para a análise dos dados foi utilizado o programa SISVAR (Programa de análises estatísticas e planejamento de experimentos) da Universidade Federal de Lavras, Lavras, Minas Gerais.

\section{RESULTADOS E DISCUSSÃO}

A cultivar Miura apresentou a melhor sobrevivência entre os quatro germoplasmas avaliados em todos os tratamentos utilizados (Tabela 3). Este material genético tem sido largamente utilizado no Brasil (Brazão, 1992), devido à precocidade vegetativa e folhas de boa qualidade, além de possuir facilidade de propagação por estaquia (Higashikawa, 2001), por estes motivos, no presente trabalho, esta foi considerada a cultivar testemunha. Nesta cultivar, os tratamentos com bagaço de cana-de-açúcar destacaram-se, com valores médios de porcentagem de sobrevivência de 96,67\% (Tabela 3). Nas demais cultivares este complemento orgânico no substrato também proporcionou bons resultados. Na cultivar IZ 6/2 o substrato puro, sem enriquecimento com resíduo resultou em bom índice de sobrevivência, no entanto, no tratamento de pré-imersão em água com substrato enriquecido com esterco de galinha não houve sobrevivência
(Tabela 3). Observa-se também pelos dados da tabela que o pré-tratamento com água por $24 \mathrm{~h}$ resultou no melhor índice de sobrevivência entre todos os substratos utilizados, estando estes de acordo com os trabalhos realizados por Okamoto et al. (2005) e Okamoto e Rodella (2006). Esta técnica pode ser muito promissora e ser facilmente adotada pelos sericicultores por sua simplicidade e baixo custo, além de proporcionar elevados índices de sobrevivência em amoreiras para a formação de glebas comerciais.

$\mathrm{O} \mathrm{pH}$ dos resíduos orgânicos variou, sendo que na presença de bagaço de cana-deaçúcar o pH ficou em 6,07 e no esterco de galinha em torno de 7,55 (Tabela 2). Estes valores são considerados relativamente altos para substratos segundo Kämpf e Fermino (2000). O valor mais baixo no bagaço de cana pode ter proporcionado melhor condição de enraizamento para as estacas de amoreira das cultivares avaliadas.

Além do $\mathrm{pH}$, outras propriedades físicas do substrato devem ser levadas em conta. Hoffmann et al. (1996) afirmam que durante o período de enraizamento da estaca, o substrato deve manter-se úmido, e suficientemente aerado. Arruda et al. (2007) em trabalho com esterco de galinha acrescido ao substrato no enraizamento de estacas de guaranazeiro, observaram maior densidade no substrato, devido a maior encharcamento o que segundo os autores afetam a oxigenação dos tecidos do sistema radicular afetando o desenvolvimento do mesmo, podendo levar a morte das estacas, que poderia justificar os baixos valores de sobrevivência encontrados no presente trabalho no substrato suplementado com esterco de galinha em todas as cultivares. Em tais substratos observou-se alta umidade em comparação com os outros substratos. A cultivar IZ 6/2 não apresentou brotação neste tratamento.

Nas Figuras 1, 2, 3 e 4 estão representados a porcentagem plantas com brotos ao longo de 25 dias para cada um dos materiais estudados. Verifica-se que houve diferença na velocidade de brotamento entre os tratamentos em cada cultivar avaliada. Estacas submetidas ao tratamento pré-plantio com imersão em água e plantio em substrato sem suplementação do resíduo orgânico (Tratamento 3) tiveram maior velocidade de brotação nas cultivares Miura (Figura 1), SK 1 
GALETI, N. C. S. et al. Estaquia de amoreiras submetidas...

(Figura 2) e SK 4 (Figura 3). Pode-se destacar o pré -tratamento com imersão em água associado ao plantio em substrato enriquecido com bagaço de cana-de-açúcar (T4) na cultivar SK-4.

TABELA 3 - Valores médios da porcentagem de sobrevivência de estacas de diferentes cultivares de amoreira em diferentes substratos com e sem pré-tratamento em água por 24 h, após 70 dias, Maringá, Paraná, 2008.

\begin{tabular}{|c|c|c|c|c|}
\hline \multirow{2}{*}{ Tratamentos } & \multicolumn{4}{|c|}{ Cultivares } \\
\hline & Miura & SK 1 & SK 4 & IZ 6/2 \\
\hline $\begin{array}{l}\text { T1-pré-tratamento com água + substrato enriquecido } \\
\text { com bagaço de cana-de-açúcar }\end{array}$ & 96,67 aA & $36,67 \mathrm{bB}$ & $60,0 \mathrm{aB}$ & $55,00 \mathrm{aB}$ \\
\hline $\begin{array}{l}\text { T2-pré-tratamento com água }+ \text { substrato enriquecido } \\
\text { com esterco de galinha }\end{array}$ & $53,33 \mathrm{bA}$ & $10,00 \mathrm{bB}$ & $40,00 \mathrm{bB}$ & - \\
\hline T3-pré-tratamento com água & $100,00 \mathrm{aA}$ & $70,00 \mathrm{aB}$ & $70,00 \mathrm{aB}$ & $73,33 \mathrm{aB}$ \\
\hline $\begin{array}{l}\text { T4-substrato enriquecido com bagaço de cana-de- } \\
\text { açúcar }\end{array}$ & $87,50 \mathrm{aA}$ & $60,00 \mathrm{aB}$ & $52,50 \mathrm{aB}$ & $52,50 \mathrm{aB}$ \\
\hline T5-substrato enriquecido com esterco de galinha & $43,33 \mathrm{bA}$ & $20,00 \mathrm{bA}$ & $30,00 \mathrm{bA}$ & $25,00 \mathrm{bA}$ \\
\hline T6-Testemunha (substrato sem enriquecimento) & $70,00 \mathrm{bA}$ & $47,50 \mathrm{aB}$ & $13,33 \mathrm{bC}$ & $70,00 \mathrm{aA}$ \\
\hline
\end{tabular}

* Médias seguidas pela mesma letra minúscula nas colunas e maiúsculas nas linhas não diferem significativamente pelo teste de Scott-Knott a $5 \%$ de probabilidade de erro. C.V. $=25,53 \%$

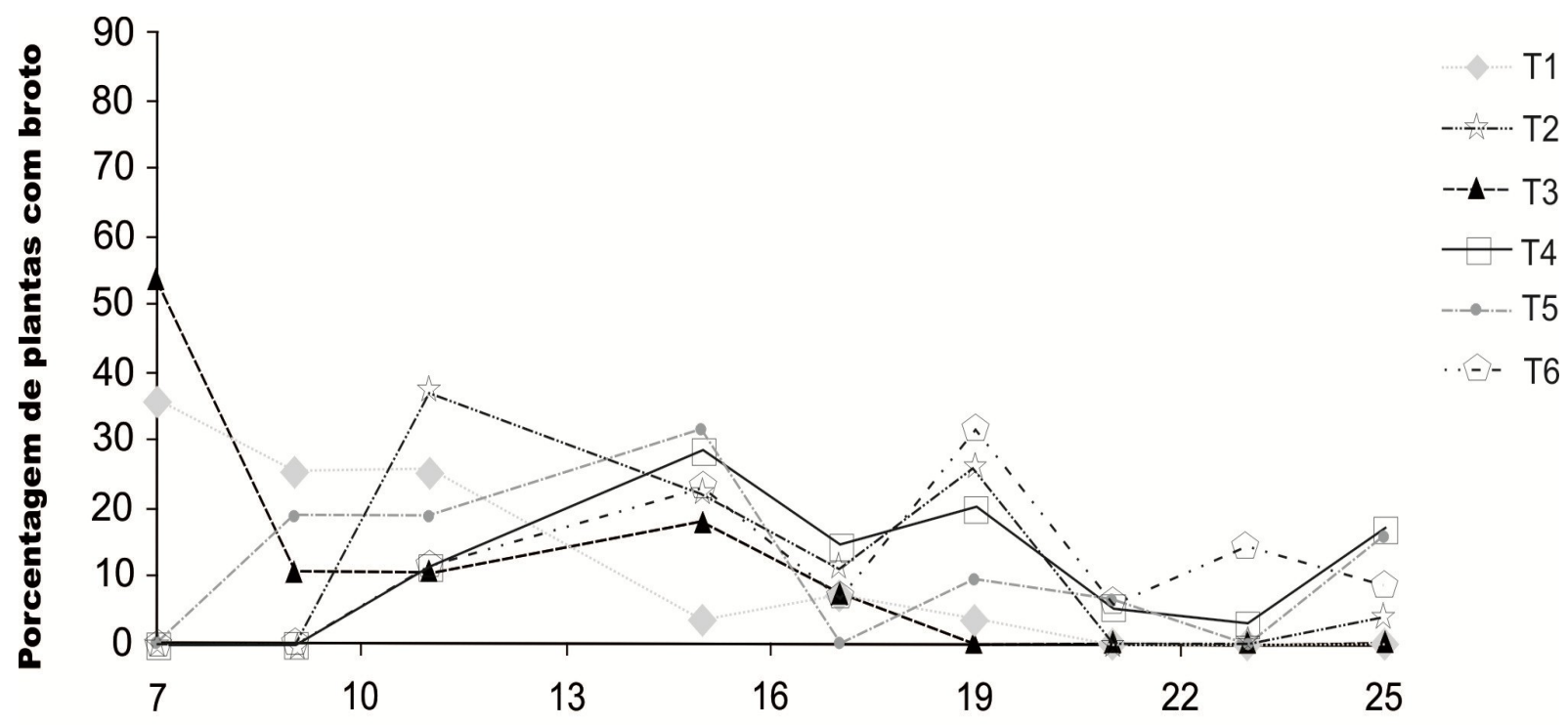

Dias após o plantio

FIGURA 1 - Porcentagem de plantas com brotos de estacas de amoreira cultivar Miura avaliados diariamente após a instalação do experimento. T1 - pré-tratamento de imersão em água e plantio em substrato enriquecido com bagaço de cana-de-açúcar; T2 - pré-tratamento de imersão em água e plantio com substrato enriquecido com esterco de galinha; T3 - pré-tratamento de imersão em água e plantio em substrato considerado Controle (3:1:1 de solo, areia e húmus); T4 - substrato enriquecido com bagaço de cana-de-açúcar; T5 - substrato enriquecido com esterco de galinha; T6 - substrato (3:1:1 de solo, areia e húmus). 
GALETI, N. C. S. et al. Estaquia de amoreiras submetidas...

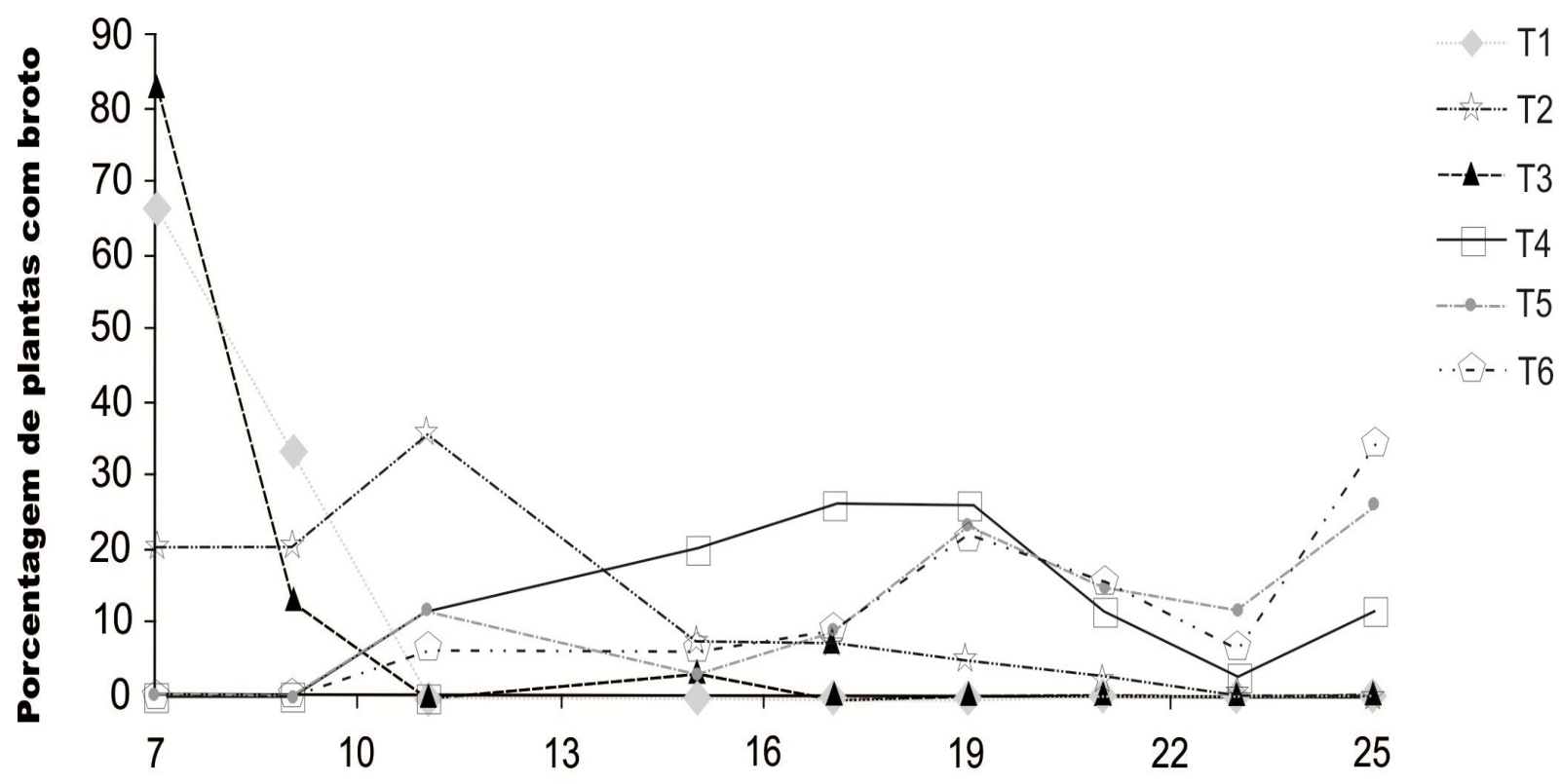

\section{Dias após o plantio}

FIGURA 2 - Porcentagem de plantas com broto de estacas de amoreira cultivar SK-1 avaliados diariamente após a instalação do experimento. T1 - pré-tratamento de imersão em água e plantio em substrato enriquecido com bagaço de cana-de-açúcar; T2 - pré-tratamento de imersão em água e plantio com substrato enriquecido com esterco de galinha; T3 - pré-tratamento de imersão em água e plantio em substrato considerado Controle ( $3: 1: 1$ de solo, areia e húmus); T4 - substrato enriquecido com bagaço de cana-de-açúcar; T5 - substrato enriquecido com esterco de galinha; T6 - substrato (3:1:1 de solo, areia e húmus).

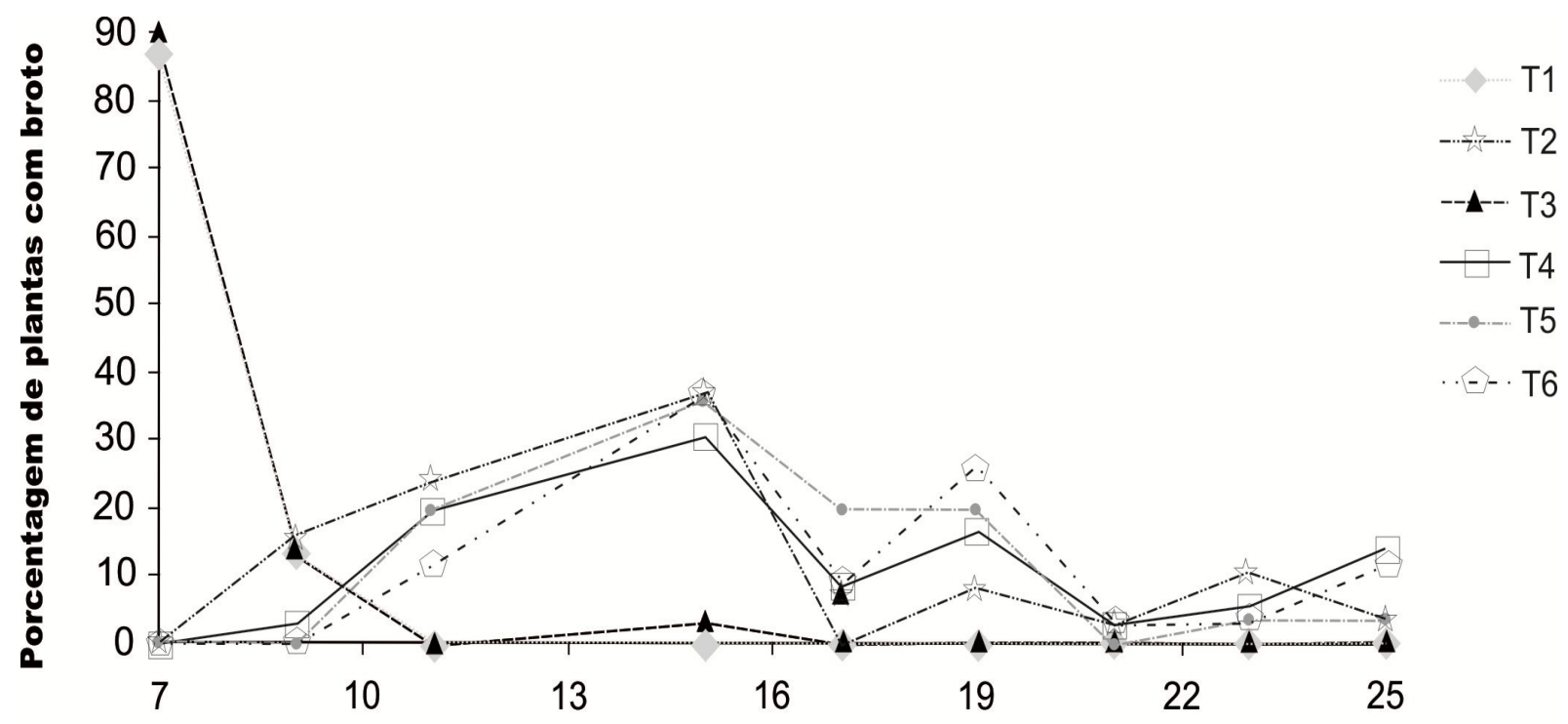

Dias após o plantio

FIGURA 3 - Porcentagem de plantas com broto de estacas de amoreira cultivar SK-4 avaliados diariamente após a instalação do experimento. T1 - pré-tratamento de imersão em água e plantio em substrato enriquecido com bagaço de cana-de-açúcar; T2 - pré-tratamento de imersão em água e plantio com substrato enriquecido com esterco de galinha; T3 - pré-tratamento de imersão em água e plantio em substrato considerado Controle (3:1:1 de solo, areia e húmus); T4 - substrato enriquecido com bagaço de cana-de-açúcar; T5 - substrato enriquecido com esterco de galinha; T6 - substrato (3:1:1 de solo, areia e húmus). 
GALETI, N. C. S. et al. Estaquia de amoreiras submetidas...

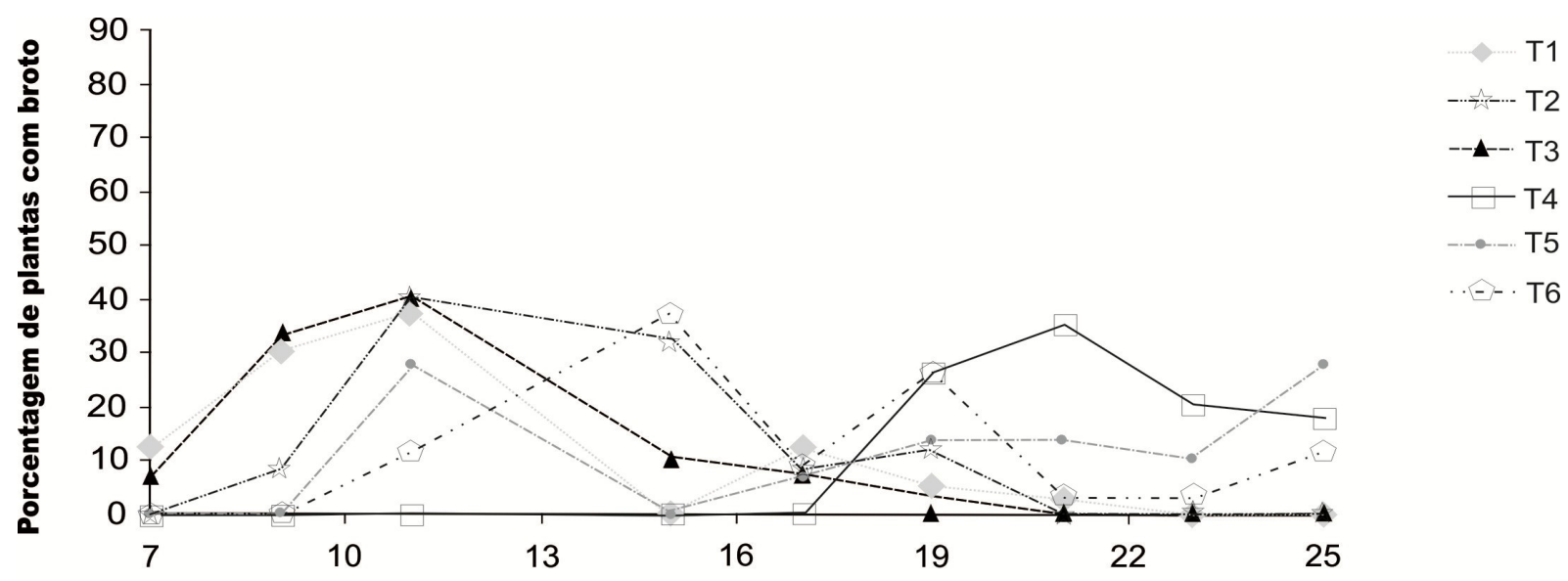

Dias após o plantio

FIGURA 4 - Porcentagem de plantas com broto de estacas de amoreira cultivar 6/2 avaliados diariamente após a instalação do experimento. T1 - pré-tratamento de imersão em água e plantio em substrato enriquecido com bagaço de cana-de-açúcar; T2 - pré-tratamento de imersão em água e plantio com substrato enriquecido com esterco de galinha; T3 - pré-tratamento de imersão em água e plantio em substrato considerado Controle (3:1:1 de solo, areia e húmus); T4 - substrato enriquecido com bagaço de cana-de-açúcar; T5 - substrato enriquecido com esterco de galinha; T6 - substrato (3:1:1 de solo, areia e húmus).

A Figura 4 reflete os valores de porcentagem de plantas com broto surgindo de forma praticamente uniforme durante o tempo de avaliação do experimento na variedade IZ 6/2.

A altura dos brotos foi influenciada pelos diferentes substratos analisados (Tabela 4). Na cultivar Miura o substrato sem suplemento orgânico cujas estacas foram pré-emergidas na água por 24 h o maior comprimento dos brotos não diferiu estatisticamente dos substratos contendo suplemento de esterco de galinha com e sem pré tratamento em imersão na água. Estacas provenientes desta mesma cultivar quando submetidas a substratos com bagaço de cana-deaçúcar após 70 dias apresentaram menor comprimento dos brotos. As estacas da cultivar SK 4 pré-tratadas enraizadas no substrato com esterco de galinha apresentaram melhor desenvolvimento, diferindo dos demais tratamentos. Nas cultivares SK 1 e IZ 6/2 não houve diferença entre os tratamentos.

TABELA 4 - Valores da altura média $(\mathrm{cm})$ dos brotos de estacas de diferentes cultivares de amoreira em diferentes substratos com e sem pré-tratamento em água por $24 \mathrm{~h}$, após 70 dias, Maringá, Paraná, 2008.

\begin{tabular}{|c|c|c|c|c|}
\hline \multirow{2}{*}{ Tratamentos } & \multicolumn{4}{|c|}{ Cultivares } \\
\hline & Miura & SK-1 & SK-4 & $6 / 2$ \\
\hline $\begin{array}{l}\text { T1-pré-tratamento com água + substrato enriquecido } \\
\text { com bagaço de cana-de-açúcar }\end{array}$ & $30,26 \mathrm{bA}$ & $19,02 \mathrm{aA}$ & $32,02 \mathrm{bA}$ & $25,50 \mathrm{aA}$ \\
\hline $\begin{array}{l}\text { T2-pré-tratamento com água }+ \text { substrato enriquecido } \\
\text { com esterco de galinha }\end{array}$ & $49,41 \mathrm{aA}$ & $22,00 \mathrm{aB}$ & $47,00 \mathrm{aA}$ & - \\
\hline T3-pré-tratamento com água & 47,23 aA & $25,75 \mathrm{aB}$ & $30,82 \mathrm{bB}$ & $31,51 \mathrm{aB}$ \\
\hline $\begin{array}{l}\text { T4-substrato enriquecido com bagaço de cana-de- } \\
\text { açúcar }\end{array}$ & $28,59 \mathrm{bA}$ & $28,00 \mathrm{aA}$ & $13,82 \mathrm{cB}$ & $25,00 \mathrm{aA}$ \\
\hline T5-substrato enriquecido com esterco de galinha & $41,41 \mathrm{aA}$ & $30,00 \mathrm{aB}$ & $36,75 \mathrm{bA}$ & $20,52 \mathrm{aB}$ \\
\hline T6-Testemunha (substrato sem enriquecimento) & $34,97 \mathrm{bA}$ & 29,17 aA & $28,83 \mathrm{bA}$ & 25,94 aA \\
\hline
\end{tabular}
teste de Scott-Knott a 5\% de probabilidade de erro. C.V. $=24,46 \%$ 
GALETI, N. C. S. et al. Estaquia de amoreiras submetidas...

De uma forma geral, o uso de esterco de galinha proporcionou bom desenvolvimento dos brotos. Segundo Bellizzi et al. (2001) o uso de esterco de galinha em amoreiral promove aumento do número e massa foliar, o que tem apresentado segundo os autores boa relação com a produção de seda em Bombyx mori. No presente estudo, mesmo se tratando de produção de mudas, pode-se supor, através de uma análise inicial, que estes materiais genéticos teriam sucesso em seu desenvolvimento quando adubados com esterco de galinha.

\section{CONCLUSÃO}

O tratamento pré-plantio com imersão por $24 \mathrm{~h}$ em água proporcionou tendência de melhores resultados de sobrevivência. Os resultados obtidos neste experimento não permitem indicar o uso dos substratos orgânicos: bagaço de cana-de-açúcar e esterco de galinha na proporção de para melhorar a sobrevivência de estacas de amoreira destinadas à sericicultura.

\section{AGRADECIMENTOS}

Os autores agradecem ao IAPAR de Londrina pelo fornecimento das estacas, em especial a Ruy Seiji Yamaoka e Namir Fillipin.

\section{REFERÊNCIAS}

1. ARRUDA, M. R.; PEREIRA, J. C. R.; MOREIRA, A.; TEIXEIRA, W. G. Enraizamento de estacas herbáceas de guaranazeiro em diferentes substratos. Ciência e Agrotecnologia, v. 31, n. 1, p. 236-241, 2007.

2. BELLIZZI, N. C.; MARCHINI, L. C.; TAKAHASHI, R. Híbridos de amoreira adubados com matéria orgânica e gesso agrícola na produção de bicho-da-seda. Scientia Agricola, v. 58, n. 2, p. 349-355, 2001.

3. BRAZÃO, C. S. Estudo da curva de crescimento e composição bromatológica da amoreira (Morus alba L.). 1992. 42 f. Monografia (Trabalho de Conclusão de Curso) - Graduação em Zootecnia. Faculdade de Ciências Agrárias e Veterinárias, UNESP, Jaboticabal, 1992.

4. CALDWELL, J. D. Blackberry propagation. HortScience, v. 19, n. 2, p. 193-195, 1984

5. HANADA, Y.; WATANABE, J. K. Manual de criação do bicho-da-seda. Curitiba: COCAMAR, 1986.

6. HIGASHIKAWA, T. Catálogo de cultivares de amoreira. Bastos: Fiação de Seda Bratac, 2001. 74 p.

7. HOFFMANN, A.; CHALFUN, N. N. J.; ANTUNES, L. E.C.; RAMOS, J. D.; PASQUAL, M.; REZENDE e SILVA, C. R. Fruticultura comercial: propagação de plantas frutíferas. Lavras: UFLA/FAEPE, 1996.

8. KÄMPF, A. N. Seleção de materiais para uso como substrato. In: KÄMPF, A. N.; FERMINO, M. H. (Ed.). Substratos para plantas: a base da produção vegetal em recipientes. Porto Alegre: Gênesis, 2000. p. 139-145.

9. MANTOVANI, R.; PAVARINI, M., P.; BARBERO, J. H.; OLIVEIRA, B. R.; GENEROSO, A. C.; TAKAHASHI, R. Influência do cultivar de amoreira (Morus sp.) e o manejo no trato alimentar na produção de casulos do bicho-da-seda (Bombyx mori L.). Boletim de Indústria Animal, v. 63, n. 2, p. 83- 87, 2006.

10. MENEGUIM, A. M.; LOVATO, L.; SILVA, R. Z.; YAMAOKA, R. S.; NAGASHIMA, G. T.; PASINI, A. Influência de cultivares de amoreira Morus spp. sobre a produção e qualidade de casulos de bicho-da-seda, Bombyx mori L. (Lepidoptera: Bombycidae). Neotropical Entomology, v. 36, n. 5, p. 670-674. 2007.

11. MIRANDA, J. E.; BONACIN, G. A.; TAKAHASHI, R. Produção e qualidade de folhas de amoreira em função da época do ano e de colheita. Scientia Agricola, v. 59, n. 3, p. 499-504, 2002.

12. MURARI, O.; MARCHINI, L. C. Influência de genótipo de amoreira (Morus sp.) e substratos no peso e características de casulos do bicho-da-seda (Bombyx mori L.). Acta Scientiarum. Animal Sciences, v. 23, n. 4, p. 1059-1063, 2001.

13. OKAMOTO, F.; PORTO, A. J.; SOUZA. A. L. P. Efeito dos tratamentos pré-plantio no sobrevivência de estacas de cultivares de amoreira (Morus spp). Boletim de Indústria Animal, v. 62, n. 4, p. 281-288, 2005.

14. OKAMOTO, F.; RODELLA, R. A. Características morfo-anatômicas e bromatológicas de folhas de amoreira em relação às preferências do bicho-da-seda. Pesquisa Agropecuária Brasileira, v. 41, n. 2, p. 195-203, 2006.

15. SEAB. SECRETARIA DA AGRICULTURA E DO ABASTECIMENTO DO PARANÁ. Relatório Takii: perfil da sericicultura no estado do Paraná, safra 2008-2009. Disponível em: <http://www.seab.pr.gov.br/arquivos/File/deral/Prognosticos/ seda_2009_10.pdf>. Acesso em: 06 abr. 2010.

16. SCOTT, A.; KNOTT, M. Cluster-analysis method for grouping means in analysis of variance. Biometrics, v. 30 , n. 3 , p. 507-512, 1974

Recebido em 14/06/2010

Aceito em 29/11/2010 
